\title{
Survival Analysis of Pathological T3a Upstaging in Clinical T1 Renal Cell Carcinoma
}

\author{
GU-SHUN LAI ${ }^{1}$, JIAN-RI LI ${ }^{2,3,4}$, SHIAN-SHIANG WANG ${ }^{2,3,5}$, CHUAN-SHU CHEN ${ }^{2,3}$, CHUN-KUANG YANG ${ }^{2}$, \\ SHENG-CHUN HUNG ${ }^{2,3}$, CHEN-LI CHENG ${ }^{2,3}$, YEN-CHUAN OU ${ }^{3,6}$ and KUN-YUAN CHIU ${ }^{2,5}$ \\ ${ }^{1}$ Division of Urology, Department of Surgery, Chiayi Branch, \\ Taichung Veterans General Hospital, Chiayi, Taiwan, R.O.C.; \\ ${ }^{2}$ Division of Urology, Department of Surgery, Taichung Veterans General Hospital, Taichung, Taiwan, R.O.C.; \\ ${ }^{3}$ Institute of Medicine, Chung Shan Medical University, Taichung, Taiwan, R.O.C.; \\ ${ }^{4}$ Department of Medicine and Nursing, Hungkuang University, Taichung, Taiwan, R.O.C.; \\ ${ }^{5}$ Department of Applied Chemistry, National Chi Nan University, Nantou, Taiwan, R.O.C.; \\ ${ }^{6}$ Department of Urology, Tung's Taichung MetroHarbor Hospital, Taichung, Taiwan, R.O.C.
}

\begin{abstract}
Aim: To evaluate the oncological outcomes of pathological T3a upstaging from clinical T1 renal cell carcinoma. Patients and Methods: We retrospectively studied patients who underwent radical or partial nephrectomy for clinical T1 renal tumors. Results: The median follow-up period was 44 months. At three and five years, the respective overall survival rate was $88.7 \%$ and $82.4 \%$ in pT3a disease, $95.7 \%$ and $93.4 \%$ in $p T 1 \quad(p=0.008)$, the cancer-specific survival rate, $93.9 \%$ and $90.8 \%$ in pT3a, $99 \%$ and $97.7 \%$ in $p T 1(p=0.001)$, and the recurrence-free survival rate, $79.7 \%$ and $71.0 \%$ in pT3a, and 95.5 and $94.3 \%$ in pT1 $(p<0.001)$. Conclusion: Patients with pathological T3a upstaging tumors were associated with a significantly decreased survival rate, along with a higher recurrence rate when compared to those with pathological T1 disease.
\end{abstract}

With the increased use of cross-sectional imaging modalities, the recognition of renal cell carcinoma (RCC) is increasing. Most new cases are detected incidentally as small renal masses in asymptomatic patients (1-3). The majority of masses are $\leq 7 \mathrm{~cm}$ in size, or at clinical stage T1 (cT1), and confined to the kidney (3). Patients with these small renal masses are generally given a favorable

This article is freely accessible online.

Correspondence to: Kun-Yuan Chiu, Division of Urology, Department of Surgery, Taichung Veterans General Hospital, No. 1650, Sec. 4, Taiwan Boulevard, Taichung 407, Taiwan, R.O.C. Tel: +886 423592525 \#5121, Fax: +886 423593160, e-mail: chiu37782002@yahoo.com

Key Words: Pathological T3a upstaging, renal cell carcinoma, survival. prognosis. Current guidelines recommend nephron-sparing surgery, such as a partial nephrectomy, for the treatment of these masses with the advantages of offering renal function preservation and equivalent oncologic outcomes when compared to traditional radical nephrectomy (4-6). However, after surgery for these small renal masses, a number of tumors are found to have pathologically upstaged to T3a (pT3a). Unfortunately, current imaging modalities have a limited ability in detecting the adverse pathologic features associated with pT3a upstaging, such as renal sinus extension, perinephric fat invasion or renal vein thrombosis, which in turn will lead to under-staging of the tumors and underestimate its seriousness if preoperatively based solely upon the size criteria.

Previous literature offers conflicting results regarding the prognosis and associated factors for pT3a upstaging (6-10). Therefore, the objective of the present study was to evaluate the oncologic outcomes of the patients with pT3a upstaging tumors, and also to identify the clinicopathological features associated with upstaging.

\section{Patients and Methods}

The present study was approved by the Institutional Review Board. We retrospectively reviewed the charts of consecutive patients who underwent radical or partial nephrectomy for the treatment of clinical T1 N0M0 renal tumors in our Institute during the period from January 2002 to June 2018. All types of surgical approaches (open, laparoscopic and robotic surgeries) were included. Clinical stages were determined by the surgeon according to the patients' documents and confirmed with preoperative Computed Tomography (CT) or Magnetic Resonance Imaging (MRI). All renal tumors were diagnosed pathologically as RCC. Patients with a diagnosis of non-RCC renal tumors on their pathologic reports, bilateral renal tumors, loss of follow-up or insufficient data for analysis were excluded. 
Table I. Patients' demographics and pathological characteristics.

\begin{tabular}{|c|c|c|c|c|c|}
\hline \multirow[b]{2}{*}{ Age, years (IQR) } & \multicolumn{2}{|c|}{$\mathrm{T} 1(\mathrm{n}=374,87.2 \%)$} & \multicolumn{2}{|c|}{$\mathrm{T} 3 \mathrm{a}(\mathrm{n}=55,12.8 \%)$} & \multirow{2}{*}{$\frac{p \text {-Value }}{0.011 *}$} \\
\hline & 59 & $(49-68)$ & 64 & $(56-75)$ & \\
\hline Gender, n (\%) & & & & & 0.214 \\
\hline Male & 256 & 68 & 33 & 60 & \\
\hline Female & 118 & 32 & 22 & 40 & \\
\hline Follow up, months (IQR) & 43 & $(20-96)$ & 44.5 & $(24-70)$ & 0.439 \\
\hline \multicolumn{6}{|l|}{ Clinical stage, $\mathrm{n}(\%)$} \\
\hline T1a & 196 & 52 & 15 & 27 & $<0.001 *$ \\
\hline $\mathrm{T} 1 \mathrm{~b}$ & 178 & 48 & 40 & 73 & \\
\hline Tumor size, $\mathrm{cm}$ & 3.9 & $2.6-5$ & 5 & $3.5-6.5$ & $<0.001^{*}$ \\
\hline \multicolumn{6}{|l|}{ Etiology of T3, n (\%) } \\
\hline Sinus fat invasion & & & 12 & 22 & \\
\hline Perinephrenic invasion & & & 26 & 47 & \\
\hline Vein thrombosis & & & 7 & 13 & \\
\hline Sinus fat invasion+vein thrombosis & & & 5 & 9 & \\
\hline Perinephrenic invasion+vein thrombosis & & & 2 & 4 & \\
\hline Collecting system invasion & & & 3 & 5 & \\
\hline \multicolumn{6}{|l|}{ Fuhrman grade, $\mathrm{n}(\%)$} \\
\hline 1 & 24 & 6 & 1 & 2 & $0.002 *$ \\
\hline 2 & 200 & 54 & 22 & 40 & \\
\hline 3 & 90 & 24 & 22 & 40 & \\
\hline 4 & 4 & 1 & 4 & 7 & \\
\hline Unknown & 56 & 15 & 6 & 11 & \\
\hline Histology, n (\%) & & & & & 0.277 \\
\hline Clear & 264 & 71 & 44 & 80 & \\
\hline Papillary & 34 & 9 & 4 & 7 & \\
\hline Chromophobe & 31 & 8 & 2 & 4 & \\
\hline Others & 45 & 12 & 5 & 9 & \\
\hline Necrosis, n (\%) & 37 & 10 & 14 & 25 & $0.03 *$ \\
\hline LVI, n $(\%)$ & 9 & 2 & 15 & 27 & $<0.001^{*}$ \\
\hline Sarcomatoid features, n (\%) & 2 & 0.5 & 4 & 7 & $<0.001^{*}$ \\
\hline Margin positive, n (\%) & 9 & 2 & 3 & 6 & 0.182 \\
\hline Method & & & & & $<0.01^{*}$ \\
\hline Radical & 234 & 63 & 48 & 87 & \\
\hline Partial & 140 & 37 & 7 & 13 & \\
\hline Recurrence, n (\%) & 23 & 6.1 & 13 & 23.6 & $<0.001 *$ \\
\hline Local recurrence & 7 & 1.9 & 2 & 3.6 & \\
\hline Distant metastasis & 16 & 4.2 & 11 & 20 & \\
\hline
\end{tabular}

IQR, Interquartile range; LVI, lymphovascular invasion.

Patients included in the present study were divided into pathologic T1 (pT1) and T3a (pT3a) groups. Patient demographics and tumor characteristics, including age, gender, tumor size, clinical stage, Fuhrman grade, histology type, margin status and pathologic features, were evaluated and compared between the two groups using the Mann-Whitney $U$-test and Fisher's exact test for continuous variables, and the Pearson's Chi-Square test for categorical variables analysis. Kaplan-Meier survival curves and the $\log$ rank test were used to investigate overall survival (OS), recurrence-free survival (RFC) and cancer-specific survival (CSS). In order to determine the clinicopathological features associated with pT3a upstaging, multivariate analyses were conducted using logistic regression. Univariate and multivariate Cox proportional hazards regression models were used to investigate the features related to disease recurrence. A $p$-value $<0.05$ was considered statistically significant, and all analyses were performed using SPSS software (version 19.0; SPSS Inc., Chicago, IL, USA).

\section{Results}

Charts were reviewed from a database of Taichung Veteran's General Hospital after approval by the Institutional Review Board. From January 2002 to June 2018, a total number of 476 patients who had underwent partial or radical nephrectomy for the treatment of clinical stage T1M0N0 renal tumors were evaluated. After excluding patients with pathological non-RCC lesions or insufficient information for analysis, 429 patients were included in the final study, of which 55 (12.8\%) were found to have renal tumors upstaged to pT3a, while $374(87.2 \%)$ were not upstaged. Patients' demographics and the clinicopathological characteristics between the two groups are shown and compared in Table I. 


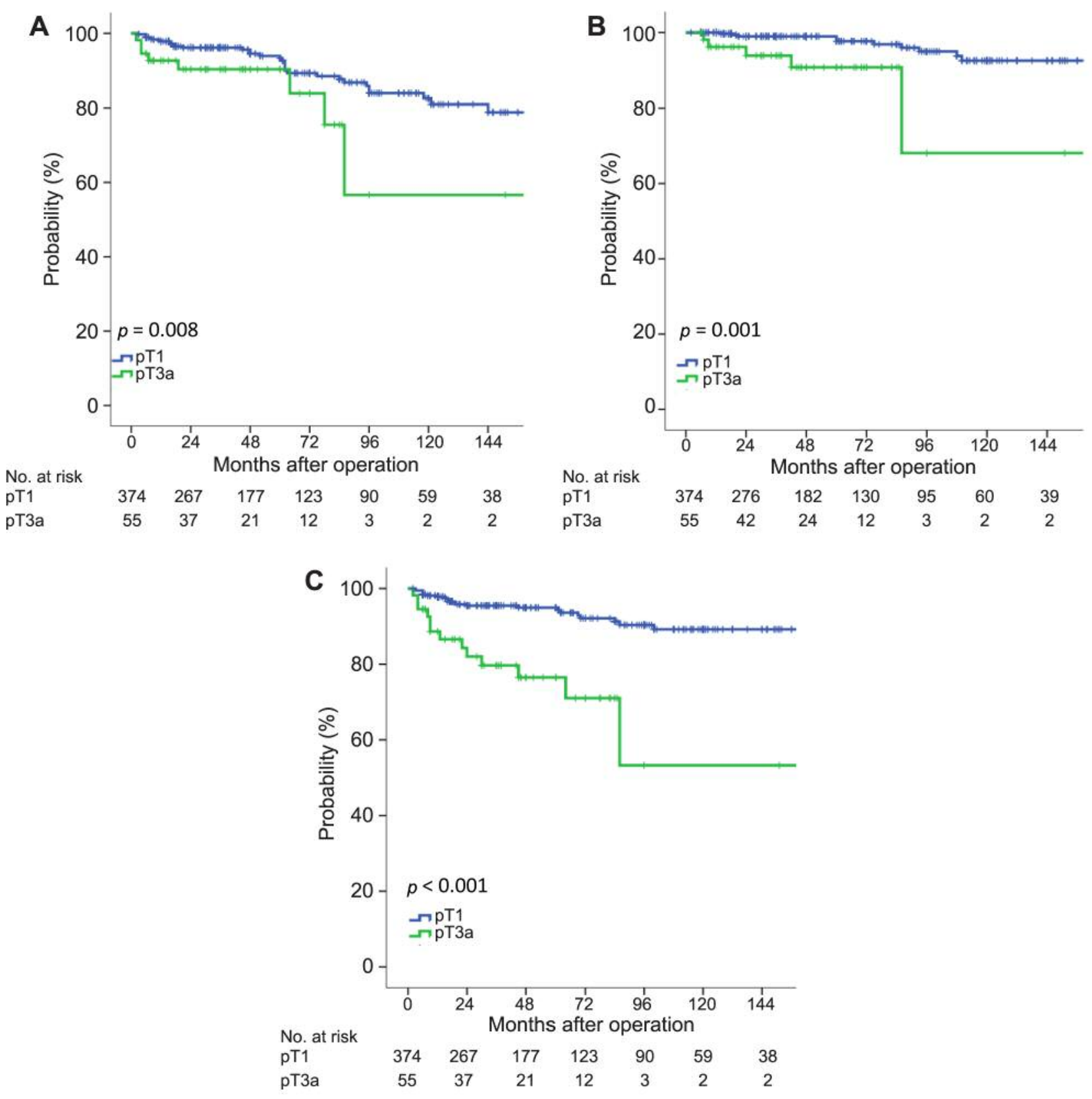

Figure 1. Kaplan-Meier curves of estimated overall survival (A), cancer-specific survival (B) and recurrence-free survival (C) after surgery between the pTla and pT3a groups.

Patients in the upstaged group were older than those in the non-upstage group (64 years vs. 59 years, $p=0.011$ ). The majority of patients were male in both groups, though there was no significant difference between the groups. When compared with the non-upstage group, the upstaged group had a greater proportion of patients with clinical T1b tumors $(73 \%$ vs. $48 \%$, $p<0.001)$, and their tumor size was larger $(5 \mathrm{~cm} v s .3 .9 \mathrm{~cm}$, $p<0.001)$. The upstaged group tended to have a higher Fuhrman grade disease level (Grade 3 and 4) than the non-upstaged group
(47\% vs. $25 \%, p=0.002$ ). Additionally, histopathological features related to poor prognosis, including tumor necrosis (25\% vs. $10 \%, p=0.03)$, lymphovascular invasion $(27 \%$ vs. $2 \%$, $p<0.001)$, sarcomatoid change ( $7 \%$ vs. $0.5 \%, p<0.001)$, were significantly more common in the upstaged group when compared to the non-upstage group. With regards to surgical methods, radical nephrectomy was performed significantly more frequently in the upstaged group than in the non-upstage group ( $87 \%$ vs. 63\%, $p<0.001$ ). During a median follow-up period of 


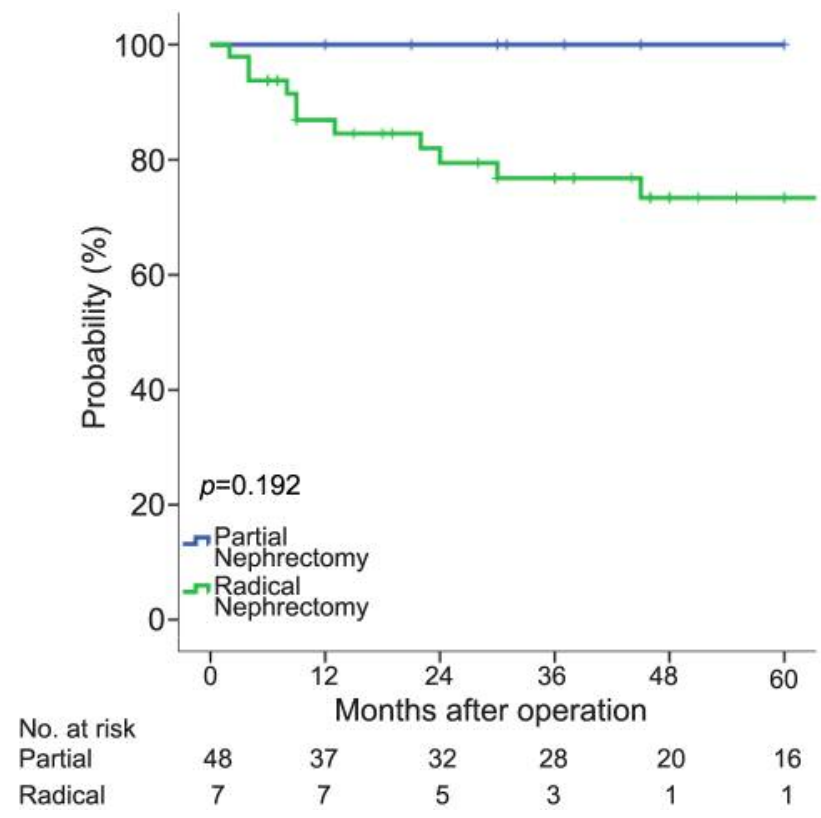

Figure 2. Recurrence-free survival between partial and radical nephrectomy for the patients with upstaged pT3a renal tumors.

44.5 months (interquartile range=24-70) after surgery, 13 $(23.6 \%)$ patients with pT3a upstaging tumors experienced tumor recurrence, of which $2(3.6 \%)$ patients had local recurrence and $11(20 \%)$ developed distant metastasis. For the non-upstage group, median follow-up was 43 months (interquartile range $=20-96)$ and disease recurrence occurred in $23(6.1 \%)$ patients, including local recurrence in $7(1.9 \%)$ and distant metastasis in $16(4.2 \%)$. Disease recurrence was significantly more common in the pT3a upstaging group compared to the non-upstage group $(23.6 \%$ vs. $6.1 \%, p<0.001)$. There was no significant difference in positive surgical margin and RCC histological type between the two groups.

For patients with pT3a upstaging disease, the 3- and 5-year OS rate was $88.7 \%$ and $82.4 \%$, compared to $95.7 \%$ and $93.4 \%$ in non-upstage group $(p=0.008)$ respectively. The 3 - and 5year CSS rate was $93.9 \%$ and $90.8 \%$ in the pT3a upstaging group, and $99 \%$ and $97.7 \%$ in the non-upstage group $(p=0.001)$ respectively. RFS at 3 and 5 years was $79.7 \%$ and $71.0 \%$ in the pT3a upstaging group, while it was 95.5 and $94.3 \%$ in the non-upstage group $(p<0.001)$ respectively. Figure 1 demonstrates the Kaplan-Meier survival curves to compare the OS, CSS and RFS between the two groups.

In the subgroup analysis for patients with pT3a upstaging renal tumors, patients treated with radical nephrectomy seemed to experience poor RFS when compared to those who underwent partial nephrectomy, but it did not reach a statistical significance $(p=0.192)$. Figure 2 shows the comparison of RFS between a radical and partial nephrectomy in the pT3a upstaging group.
Table II. Multivariate analysis of clinicopathological features associated with pathological upstaging.

\begin{tabular}{lccc}
\hline Variables & OR & $95 \%$ CI & $p$-Value \\
\hline Age & 1.03 & $1.005-1.056$ & $0.021^{*}$ \\
Gender & & & \\
$\quad$ Female & REF & & \\
$\quad$ Male & 0.616 & $0.303-1.254$ & 0.182 \\
Size & 1.328 & $1.046-1.687$ & $0.02^{*}$ \\
Fuhrman grade & & & \\
$\quad$ I/II & REF & & \\
III/IV & 2.63 & $1.313-5.270$ & $0.006^{*}$ \\
Histology & & & \\
$\quad$ Nonclear & REF & & \\
$\quad$ Clear & 2.328 & $0.964-5.624$ & 0.06 \\
Necrosis & 1.701 & $0.705-4.107$ & 0.237 \\
LVI & 8.527 & $3.053-23.817$ & $<0.001^{*}$ \\
Sarcomatoid features & 8.716 & $1.33-57.141$ & $0.024^{*}$ \\
\hline
\end{tabular}

LVI, Lymphovascular invasion.

Based upon multivariate analysis, pT3a upstaging was associated with old age [odds ratio $(\mathrm{OR})=1.03,95 \%$ confidence interval $(95 \% \mathrm{CI})=1.005-1.056, p=0.021]$, large tumor size $(\mathrm{OR}=1.328,95 \% \mathrm{CI}=1.046-1.687, p=0.02)$, high Fuhrman grade $(\mathrm{OR}=2.63,95 \% \mathrm{CI}=1.313-5.270, p=0.006)$, lymphovascular invasion $(\mathrm{LVI})(\mathrm{OR}=8.527,95 \% \mathrm{CI}=3.053-23.817, p<0.001)$ and sarcomatoid change $(\mathrm{OR}=8.716,95 \% \mathrm{CI}=1.33-57.141$, $p=0.024)$. Table II demonstrates the multivariate analysis of clinicopathologic factors associated with pathological upstaging.

Based on univariate analysis, high Fuhrman grade $(\mathrm{OR}=3.74,95 \% \mathrm{CI}=1.931-7.243, p<0.001)$, upstaging disease $(\mathrm{OR}=4.75,95 \% \mathrm{CI}=2.385-9.464, p<0.004)$, tumor necrosis $(\mathrm{OR}=3.812,95 \% \mathrm{CI}=1.818-1.785, p<0.001)$ and larger tumor size $(\mathrm{OR}=1.444,95 \% \mathrm{CI}=1.168-1.785, p=0.001)$ were related to a decreased RFS. Further multivariate analysis showed that high Fuhrman grade $(\mathrm{OR}=2.494,95 \% \mathrm{CI}=1.239-5.019$, $p=0.01)$, upstaging disease $(\mathrm{OR}=2.579,95 \% \mathrm{CI}=1.212-5.488$, $p=0.014)$ and larger tumor size $(\mathrm{OR}=1.297,95 \% \mathrm{CI}=1.033$ 1.63, $p=0.025$ ) were significantly associated with tumor recurrence. Table III lists the univariate and multivariate Cox proportional hazards regression models for disease recurrence.

In the subgroup analysis of the pT3a upstaging group, there was no clinical or histopathological features significantly associated with tumor recurrence based upon the univariate analysis (Table IV).

\section{Discussion}

We herein report our analysis of incidental pT3a upstaging from cT1 RCC in our institution, and found that pT3 upstaging was associated with inferior oncological outcomes in terms of OS, RFS and CSS when compared to the non-upstaged pT1 group. Upon multivariate analysis, clinicopathological characteristics 
Table III. Univariate and multivariate Cox proportional hazards regression models of the factors associated with disease recurrence.

\begin{tabular}{|c|c|c|c|c|c|c|}
\hline Variables & OR & $95 \% \mathrm{CI}$ & $p$-Value & OR & $95 \% \mathrm{CI}$ & $p$-Value \\
\hline Age & 1.012 & $0.987-1.037$ & 0.342 & & & \\
\hline Gender $(\mathrm{M} / \mathrm{F})$ & 0.736 & $0.377-0.736$ & 0.37 & & & \\
\hline \multicolumn{7}{|l|}{ Histology } \\
\hline Non clear & $\mathrm{REF}$ & & & & & \\
\hline Clear & 0.952 & $0.468-1.935$ & 0.892 & & & \\
\hline \multicolumn{7}{|l|}{ Fuhrman grade } \\
\hline \multicolumn{7}{|l|}{$\mathrm{I} / \mathrm{II}$} \\
\hline III/IV & 3.74 & $1.931-7.243$ & $<0.001 *$ & 2.494 & $1.239-5.019$ & $0.01 *$ \\
\hline \multicolumn{7}{|l|}{ Method } \\
\hline Partial & REF & & & & & \\
\hline Radical & 2.281 & $0.946-5.502$ & 0.066 & & & \\
\hline Margin & 0.047 & $0-225.716$ & 0.481 & & & \\
\hline Upstaging & 4.75 & $2.385-9.464$ & $<0.001^{*}$ & 2.579 & $1.212-5.488$ & $0.014 *$ \\
\hline LVI & 2.519 & $0.889-7.136$ & 0.082 & & & \\
\hline Sarcomatoid features & 2.76 & $0.374-20.374$ & 0.32 & & & \\
\hline Necrosis & 3.812 & $1.818-7.991$ & $<0.001 *$ & 1.953 & $0.88-4.331$ & 0.1 \\
\hline Size & 1.444 & $1.168-1.785$ & $0.001 *$ & 1.297 & $1.033-1.63$ & $0.025 *$ \\
\hline
\end{tabular}

LVI, Lymphovascular invasion.

related to pT3a upstaging included old age, large tumor size, LVI and sarcomatoid change. We also found a positive relationship between pathological features (high Fuhrman grade, large tumor size and upstaged tumor) and a higher tumor recurrence rate based upon the multivariate analysis. For patients with pT3a upstaging disease, there were no significant factors identified that were related to tumor recurrence.

Several pieces of literature have reported on the impact of pT3a upstaging on prognosis, but results are conflicting. Some studies $(8,10)$ demonstrated that there was no significant difference regarding the oncologic outcomes, while the others showed inferior RFS (7, 9, 11), CSS (12) and OS (12) within the pT3a upstaging group. Our study also found that patients with pT3a upstaging disease experienced reduced 3- and 5year OS, CSS and RFS rates. Given the inferior survival outcomes due to pT3a upstaging, counseling each patient regarding the severity of the disease, along with providing an intense follow-up protocol after surgery is warranted.

The prognosis for pT3a upstaging disease in our study was inferior to previously published literature that demonstrated a RFS rate between $86 \%$ and $98 \%$ with follow-up periods up to 5 years $(7-8,10)$. In contrast, the present study showed that the RFS at 3 and 5 years was $79.7 \%$ and $71.0 \%$, respectively, for the pT3a upstaging group, that was similar to the studies conducted by Nayak et al. (9) and Russel et al. (12), which reported that the 3-year RFS was $76 \%$ and $81 \%$, respectively.

The incidence rate of pT3a upstaging in the present study was $12.8 \%$, which was consistent with previous studies that demonstrated the upstaging rate to be approximately $4.8-13 \%$ (7-9), with one study conducted by Robert et al. even reporting a higher incidence rate of up to $31 \%$ (10). Given the fact that
Table IV. Univariate analysis of factors related to tumor recurrence in pT3a upstaging group.

\begin{tabular}{lccc}
\hline Variables & OR & $95 \%$ CI & $p$-Value \\
\hline Age & 0.989 & $0.95-1.03$ & 0.596 \\
Gender (M/F) & 0.725 & $0.242-2.168$ & 0.565 \\
Histology & & & \\
$\quad$ Non clear & REF & & \\
$\quad$ Clear & 0.723 & $0.198-2.639$ & 0.624 \\
Fuhrman Grade & & & \\
I/II & & & \\
III/IV & 1.885 & $0.61-5.826$ & 0.271 \\
Method & & & \\
$\quad$ Partial & REF & & \\
$\quad$ Radical & 25.102 & $0.012-50432$ & 0.406 \\
Margin & 0.045 & $0-3586.5$ & 0.591 \\
LVI & 1.327 & $0.408-4.314$ & 0.638 \\
Sarcomatoid features & 0.043 & $0-495.347$ & 0.51 \\
Necrosis & 1.056 & $0.285-3.912$ & 0.935 \\
Size & 1.416 & $0.965-2.079$ & 0.075 \\
\hline
\end{tabular}

LVI, Lymphovascular invasion.

incidence rate was not uncommon and survival outcomes were reduced, identifying factors related to upstaging is helpful for a surgeon when considering risk stratification and preoperatively determining the optimal treatment plan.

Regarding the multivariate analysis, pathological upstaging was associated with old age, larger tumor size, high Fuhrman grade, LVI and sarcomatoid change. Clear cell type RCC was related to upstaging, but did not reach statistical significance. $(\mathrm{OR}=2.328,95 \% \mathrm{CI}=0.964-5.624, p=0.06)$. Larger tumor size 
(7-10) and high Fuhrman grade (9) have been reported to be predictors for pathological upstaging. Additional predictive factors previously described include a tumor's central location (7), clear cell type (8), positive surgical margin (8) and a high R.E.N.A.L. nephrometry score (13). Current NCCN guidelines recommend partial nephrectomy, radical nephrectomy, active surveillance, or ablation therapy for the management of small renal tumors (14). Using preoperative cross-section image or tumor biopsy results, all of these predictive factors associated with upstaging can provide useful information during the decision-making process with regards to treatment plans and operation methods.

Several histopathological characteristics, including high Fuhrman grade, positive surgical margin, LVI, sarcomatoid change, tumor necrosis, preoperative anemia and lymph nodes involvement have been proven to be associated with inferior survival outcomes for RCC (15-18). The present study demonstrated that there was no factor associated with tumor recurrence in the pT3a upstaging group, which is similar to the study conducted by Russel et al. (12). This can be attributed to the fact that pT3a upstaging itself is associated with locally advanced disease, with a tendency for local recurrence or distant metastasis. Therefore, RCC recurrence tended to occur due to the aggressive nature of pathological upstaging, rather than any other clinical or histopathological factors.

The present study revealed that high Fuhrman grade, pathological upstaging and large tumor size were predictive factors of tumor recurrence upon the multivariate analysis. A previous study by Nayak et al. (9) reported that old age, high Fuhrman grade, positive surgical margin, pathological upstaging and large tumor size were all related to RCC recurrence. They also found that positive surgical margin was a strong predictor of tumor recurrence in their cohort $(\mathrm{OR}=3.08,95 \% \mathrm{CI}=1.51$ $6.03, p=0.02$ ). The association between positive surgical margin and tumor recurrence has been controversial. Previous literature revealed that positive surgical margin or adjacent renal tissue were associated with higher recurrence (19-21), while some studies have shown that it was not related to tumor recurrence $(22,23)$. In the present study, positive surgical margin was not associated with tumor recurrence. In fact, all of the 12 patients with positive surgical margin (3 treated with radical nephrectomy and 8 with partial nephrectomy) did not receive adjuvant therapy and none of them experienced disease recurrence during the follow-up period, however, cautious surveillance remains necessary for these patients.

Whether the surgical approaches (radical or partial nephrectomy) have an impact on the survival outcomes for upstaging disease remains unclear. A previously published series by Shah $e t$ al. showed that partial nephrectomy was associated with inferior RFS, when compared with radical nephrectomy for pT3a upstaging renal tumors (18). However, Jeong et al. demonstrated that there was no difference in RFS between either partial or radical nephrectomy (11). Our series also discovered that there was no difference between the two surgical approaches. Interestingly, patients in the present study with upstaging disease treated with radical nephrectomy seemed to have a higher risk of recurrence, although it did not reach statistical significance ( $\mathrm{OR}=25.102,95 \% \mathrm{CI}=0.012-50432$, $p=0.406$ ). In fact, all patients with upstaging disease and RCC recurrence in the present study were treated with radical nephrectomy, and the vast majority involved distant metastasis (96.4\%). Selection biases existed because the operating surgeon would prefer performing radical nephrectomy over partial nephrectomy for the larger or more technically challenging renal tumors, resulting inferior outcomes. Therefore, for patients with upstaging disease, radical nephrectomy appears not to provide survival benefits over partial nephrectomy, and as such adjuvant systemic therapy may be considered for these patients given the fact that most recurrence arises from distant metastasis other than local recurrence.

There were several limitations in the present study. First, this was a retrospective, non-randomized study from a single institution, which will result in several biases. Second, the current series included various surgical methods, such as open $v s$. minimally invasive approaches, or partial $v s$. radial nephrectomy, and these would be confounding factors. Third, the present study had a small sample size, with a difference in the case numbers between the two groups. Despite these limitations, we believe that our study may provide useful information regarding renal tumors with pT3a upstaging.

In conclusion, we demonstrated that renal tumors with pathological upstaging to T3a were related to significantly decreased RFS, CSS and OS rates when compared with pT1 renal tumors. Several clinicopathological characteristics associated with upstaging disease and RCC recurrence were identified, all of which could help clinicians in risk stratification, decision making, and arranging an appropriate follow-up schedule.

\section{Conflicts of Interest}

The Authors have no conflicts of interest to declare regarding this study.

\section{Authors' Contributions}

Study design and conception: Gu-Shun Lai and Jian-Ri Li. Interpretation of data and drafting of the manuscript: Gu-Shun Lai. Acquisition of data: Shian-Shiang Wang, Chuan-Shu Chen, Chun-Kuang Yang, Sheng-Chun Hung, Chen-Li Cheng, Yen-Chuan Ou and Kun-Yuan Chiu.

\section{References}

1 Nini A, Muttin F, Cianflone F, Dehò F, Matloob R, DI Trapani D, Freschi M, Salonia A, Briganti A, Montorsi F, Bertini R and Capitanio U: Pathological high-risk renal cell carcinoma: Trends in clinical characteristics over 25 years. Anticancer Res 38(7): 4123-4130, 2018. PMID: 29970539. DOI: 10.21873/anticanres. 12703 
2 Hollingsworth JM, Miller DC, Daignault S and Hollenbeck BK: Rising incidence of small renal masses: a need to reassess treatment effect. J Natl Cancer Inst 98(18): 1331-1334, 2006. PMID: 16985252. DOI: 10.1093/jnci/djj362

3 Laguna MP, Algaba F, Cadeddu J, Clayman R Gill I, Gueglio G, Hohenfellner M, Joyce A, Landman J, Lee B and van Poppel $\mathrm{H}$ : Current patterns of presentation and treatment of renal masses: a clinical research office of the endourological society prospective study. J Endourol 28: 861-870, 2014. PMID: 24555480. DOI: 10.1089/end.2013.0724

4 Campbell SC, Novick AC, Belldegrun A, Blute ML, Chow GK, Derweesh IH, Faraday MM, Kaouk JH, Leveillee RJ, Matin SF, Russo P and Uzzo RG: Guideline for management of the clinical T1 renal mass. J Urol 182: 1271-1279, 2009. PMID: 19683266. DOI: 10.1016/j.juro.2009.07.004

5 Rendon RA, Kapoor A, Breau R, Leveridge M, Feifer A, Black $\mathrm{PC}$ and So A: Surgical management of renal cell carcinoma: Canadian Kidney Cancer Forum Consensus. Can Urol Assoc J 8: E398-E412, 2014. PMID: 25024794. DOI: 10.5489/cuaj.1894

6 Ljungberg B, Bensalah K, Canfield S, Dabestani S, Hofmann F, Hora M, Kuczyk MA, Lam T, Marconi L, Merseburger AS, Mulders P, Powles T, Staehler M, Volpe A and Bex A: EAU guidelines on renal cell carcinoma: 2014 update. Eur Urol 67: 913924, 2015. PMID: 25616710. DOI: 10.1016/j.eururo.2015.01.005

7 Gorin MA, Ball MW, Pierorazio PM, Tanagho YS, Bhayani SB, Kaouk JH, Rogers CG, Stifelman MD, Khalifeh A, Kumar R, Sivarajan G and Allaf ME: Outcomes and predictors of clinical $\mathrm{T} 1$ to pathological T3a tumor up-staging after robotic partial nephrectomy: a multi-institutional analysis. J Urol 190: 19071911, 2013. PMID: 23764083. DOI: 10.1016/j.juro.2013.06.014

8 Ramaswamy K, Kheterpal E, Pham H, Pham H, Mohan S, Stifelman M, Taneja S and Huang WC: Significance of pathologic T3a upstaging in clinical T1 renal masses undergoing nephrectomy. Clin Genitourin Cancer 13: 344-349, 2015. PMID: 25680295. DOI: 10.1016/j.clgc.2015.01.001

9 Nayak JG, Patel P, Saarela O, Liu Z, Kapoor A, Finelli A, Tanguay S, Rendon R, Moore R, Black PC, Lacombe L, Breau RH, Kawakami J, Drachenberg DE: Pathological upstaging of clinical T1 to pathological T3a renal cell carcinoma: A multiinstitutional analysis of short-term outcomes. Urology 94: 154160, 2016. PMID: 27041471. DOI: 10.1016/j.urology.2016.03.029

10 Roberts WW, Bhayani SB, Allaf ME, Chan TY, Kavoussi LR and Jarrett TW: Pathological stage does not alter the prognosis for renal lesions determined to be stage $\mathrm{T} 1$ by computerized tomography. J Urol 173: 713-715, 2005. PMID: 15711249. DOI: 10.1097/01.ju.0000153638.15018.58

11 Jeong SH, Kim JK, Park J, Jeon HJ, Yoon MY, Jeong CW, Ku JH, Kim HH and Kwak C: Pathological T3a upstaging of clinical T1 renal cell carcinoma: Outcomes according to surgical technique and predictors of upstaging. PLoS One 11: e0166183, 2016. PMID: 27861519. DOI: 10.1371/journal.pone.0166183

12 Russell CM, Lebastchi AH, Chipollini J, Niemann A, Mehra R, Morgan TM, Miller DC, Palapattu GS, Hafez KS, Sexton WJ, Spiess PE and Weizer AZ: Multi-institutional survival analysis of incidental pathologic T3a upstaging in clinical T1 renal cell carcinoma following partial nephrectomy. Urology 117: 95-100, 2018. PMID: 29678662. DOI: 10.1016/j.urology.2018.04.002

13 Tay MH, Thamboo TP, Wu FM, Zhaojin C, Choo TB, Ramaan L and Tiong HY: High R.E.N.A.L. Nephrometry scores are associated with pathologic upstaging of clinical T1 renal-cell carcinomas in radical nephrectomy specimens: implications for nephron-sparing surgery. J Endourol 28(9): 1138-1142, 2014. PMID: 24810993. DOI: 10.1089/end.2014.0123

14 Motzer RJ, Jonasch E, Agarwal N, Bhayani S, Bro WP, Chang SS, Choueiri TK, Costello BA, Derweesh IH, Fishman M, Gallagher TH, Gore JL, Hancock SL, Harrison MR, Kim W, Kyriakopoulos C, LaGrange C, Lam ET, Lau C, Michaelson MD, Olencki T, Pierorazio PM, Plimack ER, Redman BG, Shuch B, Somer B, Sonpavde G, Sosman J, Dwyer M and Kumar R: NCCN Clinical Practice Guidelines in Oncology: Kidney Cancer, Version 2.2017. J Natl Compr Canc Netw 15(6): 804-834, 2017. PMID: 28596261. DOI: 10.6004/jnccn.2017.0100

15 Dall'Oglio MF, Arap MA, Antunes AA, Cury J, Leite KR and Srougi M: Impact of clinicopathological parameters in patients treated for renal cell carcinoma. J Urol 177: 1687-1691, 2007. PMID: 17437783. DOI: 10.1016/j.juro.2007.01.065

16 Kontak JA and Campbell SC: Prognostic factors in renal cell carcinoma. Urol Clin North Am 30: 467-480, 2003. PMID: 12953749. DOI: 10.1016/s0094-0143(03)00020-X

$17 \mathrm{Xia} \mathrm{L}, \mathrm{Hu}$ G and Guzzo TJ: Prognostic significance of preoperative anemia in patients undergoing surgery for renal cell carcinoma: A meta-analysis. Anticancer Res 37(6): 3175-3181, 2017. PMID: 28551661 DOI: 10.21873/anticanres.11677

18 Shah PH, Moreira DM, Okhunov Z, Patel VR, Chopra S, Razmaria AA, Alom M, George AK, Yaskiv O, Schwartz MJ, Desai M, Vira MA, Richstone L, Landman J, Shalhav AL, Gill I and Kavoussi LR: Positive surgical margins increase risk of recurrence after partial nephrectomy for high risk renal tumors. J Urol 196: 327-334, 2016. PMID: 26907508. DOI: 10.1016/ j.juro.2016.02.075

19 Kryvenko ON: Positive surgical margins increase risk of recurrence after partial nephrectomy for high risk renal tumors. Urol Oncol 35(6): 449-450, 2017. PMID: 28416109. DOI: 10.1016/j.urolonc.2017.03.013

20 Marchinena PG, Tirapegui S, Gonzalez IT, Jurado A and Gueglio G: Positive surgical margins are predictors of local recurrence in conservative kidney surgery for pT1 tumors. Int Braz J Urol 44(3): 475-482, 2018. PMID: 29368873. DOI: 10.1590/ S1677-5538.IBJU.2017.0039

21 Aufderklamm S, Hennenlotter J, Todenhöfer T, Senghaas N, Scharpf M, Gakis G, Rausch S, Mischinger J, Bier S, Stenzl A, Schwentner C and Bedke J: Oncologic impact of renal tissue adjacent to renal cell carcinoma. Anticancer Res 36(6): 28652869, 2016. PMID: 27272798.

22 Kang HW, Lee SK, Kim WT, Yun SJ, Lee SC, Kim WJ, Hwang EC, Kang SH, Hong SH, Chung J, Kwon TG, Kim HH, Kwak C, Byun SS and Kim YJ: Surgical margin does not influence recurrence rate in pT1 clear cell renal cell carcinoma after partial nephrectomy: A multicenter study. J Surg Oncol 14(1): 70-74, 2016. PMID: 27074886. DOI: 10.1002/jso.24259

23 Sundaram V, Figenshau RS, Roytman TM, Kibel AS, Grubb RL 3rd, Bullock A, Benway BM and Bhayani SB: Positive margin during partial nephrectomy: does cancer remain in the renal remnant? Urology 77(6): 1400-1403, 2011. PMID: 21411126. DOI: $10.1016 /$ j.urology.2010.12.016

Received December 7, 2019

Revised December 20, 2019

Accepted January 4, 2020 